\title{
Personal Learning Environments and Open Educational Resources in Higher Education
}

\author{
Esteban Vázquez-Cano \\ Universidad Nacional de Educación a Distancia
}

\begin{abstract}
Resumen: Este artículo presenta, desde un enfoque teórico, la funcionalidad didáctica de los Entornos Virtuales de Aprendizaje (EVA) y los Recursos Educativos en Abierto (REA) en la Educación Superior. El tratamiento conjunto de ambas estrategias didácticas ha revelado en recientes investigaciones que el uso combinado de EVA y REA diseñados por los propios estudiantes mejora su competencia digital, principalmente en habilidades como: acceder y buscar información en la red, articular y encontrar información relevante, seleccionar los recursos de manera eficiente durante la navegación y crear estrategias personales con respecto al tratamiento de la información. Asimismo, algunos de los beneficios que produce el desarrollo de EVA y REA son: un modelo didáctico centrado en el alumno, el desarrollo de estrategias de gestión del conocimiento y la formación de un modelo autorregulado de aprendizaje.

Palabras clave: Entornos Virtuales de Aprendizaje, Recursos Educativos en Abierto, Educación Superior, competencias, métodos de aprendizaje.

Abstract: This paper presents from a theoretical approach the didactic functionality of Personal Learning Environments (PLEs) and Open Educational Resources (OERs) in Higher Education. The combination of both didactic strategies in recent studies show that the joint use of PLEs and OERs designed by students improves their digital competence, mainly in capabilities such as: accessing and searching for online information; articulating information needs; finding relevant information; selecting resources effectively; navigating between online sources; and creating personal information strategies. Furthermore, the main benefits of the implementation of PLEs and OERs are: a student-centric approach, the development of personal knowledge management strategies and the formation of a self-regulated learning model.

Keywords: Personal Learning Environment, Open Educational Resources, Higher Education, competences, teaching methods.
\end{abstract}

\section{Introduction}

The current context of massive and open education is changing the methodological paradigm of Higher Education towards the development of a methodology oriented to video-simulation and self-creation content (Vázquez-Cano, et al., 2016). Due to this new educational change, a plethora of emerging web applications and widget-based aggregation tools provide numerous options for learners to access, synthesize, organize, and create content. At the same time, networked individuals enjoy unprecedented access to subject matter experts and open opportunities to collaborate with fellow learners around the globe. The convergence of these capabilities paved the way for massive open online courses (MOOCs) and personal learning environments (PLEs) focused on learner construction (López Meneses, et al., 2015). PLEs can be seen as the spaces in which people interact and communicate and whose ultimate result is learning and the development of collective know-how. In terms of technology, PLEs are made-up of a collection of loosely coupled tools, including Web 2.0 technologies, used for working, learning, reflection 
and collaboration with others. In this academic and social context, the role of teachers should focus on two aspects: first, as a precursor of a methodology consistent with the new paradigms collaborative and mediated by ICTs and, second, as a content creator in fully accessible formats for integration into a ubiquitous, mobile, and visual universe (Vázquez-Cano, 2014; Sevillano, \& Vázquez-Cano, 2015).

Higher Education institutions can play a critical role in supporting their teaching staff in the creation of effective teaching and learning environments for students and providing ongoing opportunities for professional development. Identifying and developing learning resources are both integral parts of this process. Institutions should aspire both to create OER and to use OER from elsewhere (Vázquez-Cano, et al., 2013). Students must be proficient in both decoding and encoding multimedia materials for developing their skills in Higher Education. In this context, increased online access to OER has further promoted individualized study, which, coupled with social networking and collaborative learning, has created opportunities for pedagogical innovation. Learning occurs through interaction between members of a learning community; these learning interactions are considered learning activities; and the learning activities can take the form of words, written and spoken, images, video, multimedia, etc. (Downes, 2007).

In this paper, we will deal with the development of PLEs from the point of view of the materials for the creation and sharing of content, both for teachers and students. We need to consider learners not only as the subjects of learning, entities to whom we deliver learning content, but also the sources of learning, functioning as the perceptual input for the wider network. We concur with Fuchs (2005) that the Internet should not be considered as a mere technological system, but as a socio-technological system by encouraging PLEs and Open Educational Resources (OER) inside them, learners are also taught how to construct, regulate, and control their own learning; thus creating a lifelong learner. From a social and pedagogical perspective OER could support lifelong learning and personalized learning, therefore, it is important to explore how learning takes place within the framework of OER. OER embedded in personal learning environments will move the power over learning from the institutions, to individual learners. In this context, teaching and learning material is not necessarily created by one teacher or even by a teacher at all; learners should be actively involved in the process of designing curricula and syllabi and in the creation of knowledge (López Meneses, et al., 2014; Martín-Monje, et al., 2015).

All of us in Higher Education need to ask ourselves several questions: Can we continue to operate on the assumption that the formal curriculum is the center of the undergraduate experience? Where are the high-impact practices located? and How can students "learn to be," through both the formal and the experiential curriculum?

\section{PLEs and their development in Higher Education}

\subsection{Characteristics of PLEs}

The most important idea related to PLEs is that is not an application (Attwell, 2007; WILSON, 2008); it is a concept for organizing learning. Graham Attwell (2010), one of the first researchers to write about personal learning environments, defined them as "the spaces in which people interact and communicate and whose ultimate result is learning and the development of collective know-how. The idea of the personal learning environment is that it performs many of the functions of a content management system and of a social network system but from the perspective of the individual rather than the community or the institution (Attwell, 2007). In relation to technology, PLEs are configured with a collection of 2.0 tools which can be 
used for working, learning, reflection and collaboration with others. These digital environments give learners more control by allowing them to adapt their learning experience and connecting with other students, teachers and researchers.

The main characteristics of PLEs are: first, they are mobile, flexible and not context dependent. They can move from one domain to another and make connections between them. Second, PLEs can support and facilitate a greater variety of relationships than traditional educational media. These include relationships within and between networks and communities of practice and support for collaborative working. And third, PLEs support a greater range of learning discourses than traditional educational technology. PLEs are able to link knowledge assets with people, communities and informal knowledge (Attwell, 2010; Downes, 2010; Griff, \& Matter, 2013) and support the development of social networks for learning. For this purpose, a PLE can use social software for informal learning which is learner driven, problem-based and motivated by interest that reinforces collaboration, community engagement and of embedding learning into working and living processes generating a "community of innovation".

To effectively perform all these functions PLEs must be able to also support mobile communication devices (Drexler, 2010; Mercier, \& Higgins, 2013) and integrate various digital resources than can be developed in community and available for all learners. A network of PLEs is a learning network.

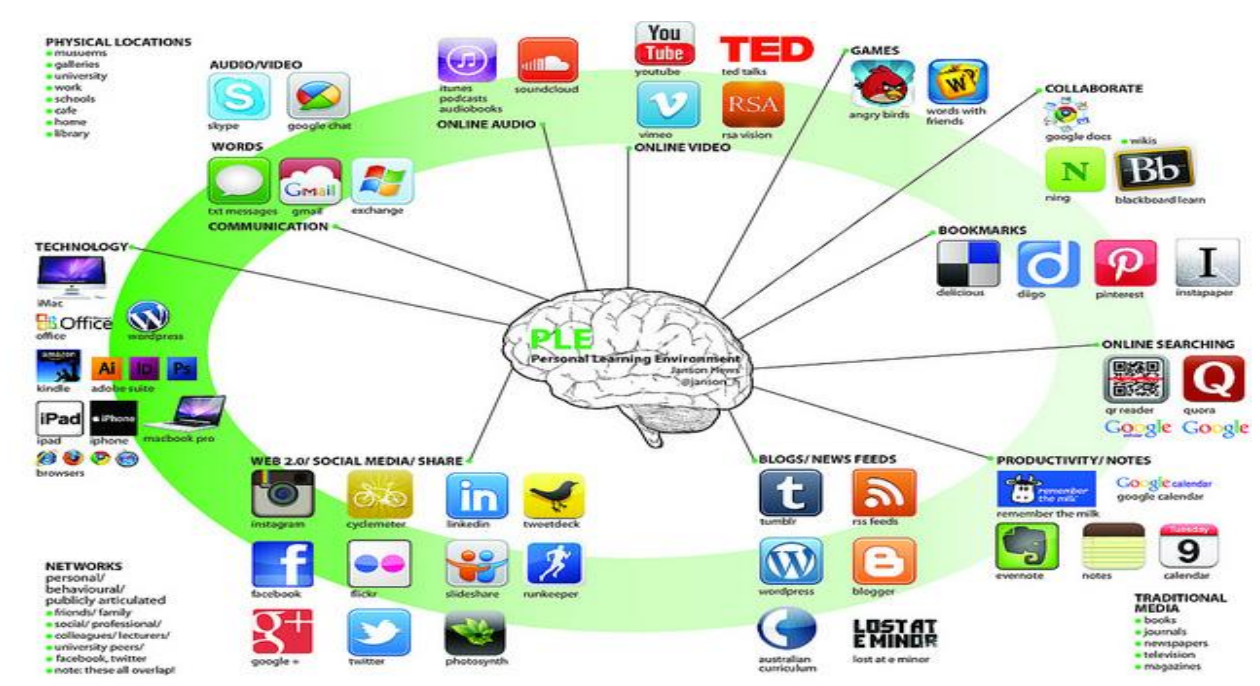

Figure 1. Characteristics of PLEs. Photo credit: Janson Hews)

Despite these advantages, PLEs have to overcome some disadvantages:

- They rarely propose specialized learning content and tools.

- Insufficient visual tutorials for building personal learning spaces or semantic tools usage.

- Insufficient collection of easy-to-use semantic tools.

- Problems in searching of relevant content.

- Needs of significant computer skills for arranging good PLE space. 


\subsection{PLEs in Higher Education}

This concept describes what is happening in Higher Education now. We can see disruption in the new forms of course delivery (i.e. Udacity, Cousera), teaching methods (i.e. flipped classrooms), and new learning models (i.e. competency based learning). These experimental forms of teaching (MOOCs) and assessing (peer review, assessment centers) are changing how educators teach, and impact the student/instructor relationship. Nowadays current learning systems are teacher or institution-centered learning environments based on institutions, universities, teachers, courses, terms, timetables, etc.; it is based on the needs of the institution rather than the learner (Downes, 2010; Alloway et al., 2013).

We might say that the formal curriculum is being pressured from two sides. On the one side is a growing body of data about the power of experiential learning in the co-curriculum; and on the other side, is the world of informal learning and the participatory culture of the Internet (Bass, 2012; Singh, \& Holt, 2013). The subjects and courses offered are limited because they cannot adapt to the rapidly changing environments; they are developed for the average student; they are typically isolated from other bodies of knowledge; and they are on a timeline (HALL, 2010). Institutions offer learning services based on Learning Management Services (LMS) as Spanish National University of Distance Education (UNED) offer to their students called aLF; where each course stops and starts on a prescribed time schedule. These learning services which are used for almost any Higher Institution are called virtual learning environments (VLE) or learning management systems (LMS).

These systems do not support lifelong learning, and additionally, a learner cannot continue to access content after he or she graduates. These systems are really good for developing formal studies and subjects of the different university degrees but they fall short in delivering open materials and integrating the socio-digital learners' environment. Learners desire a learning system allowing for anywhere, anytime, and anyone learning opportunities (Sánchez, \& García-Rodicio, 2013). Personal learning environments (PLE) give the opportunity to integrate and cerate OER and allow students to control their own learning. While Higher Education has been the predominate force in formal learning, it seems that more and more individuals are using PLEs. PLEs incorporate the strengths of constructivism and connectivism learning theories as well as those of self-directed learning and empower self-directed learners to access and control their learning (Brown, 2009; Cheung, \& Vogel, 2013).

The current trend should be to develop PLEs inside the LMS provided by Universities and in that way the learner could continue developing knowledge and interactions when formal learning has ended. One of the main strengths of PLEs is the varied resources that can be accessed and controlled. In the Personal Learning Environments Reference Model Project conducted by the University of Bolton in 2006, researchers identified 77 different patterns of use; they arranged these patterns in 8 categories: chat and messaging tools; groupware and community tools; calendaring, scheduling, and time management tools; news aggregation tools; weblogging and personal publishing tools; social software; authoring and collaboration tools; and integration tools (Wilson, 2008). Moreover, there are 2.0 tools and open-source materials such as mini-videos, concept maps or portfolios which can be freely accessed in PLEs and can be created and adapted by students and teachers (Sevillano, \& Vázquez-Cano, 2015; Vázquez-Cano, \& Sevillano, 2015). 


\section{OER: creation and sharing digital contents}

According to UNESCO, "the concept of Open Educational Resources (OER) describes any educational resources (including curriculum maps, course materials, textbooks, streaming videos, multimedia applications, podcasts, and any other materials that have been designed for use in teaching and learning) that are openly available for use by educators and students, without an accompanying need to pay royalties or license fees. In addition, "the term OER is largely synonymous with another term: Open CourseWare, or OCW, although the latter may be used to refer to a specific, more structured subset of OER. The concept of Open Educational Resources (OER) was originally coined during a UNESCO Forum on Open Courseware for Higher Education in Developing Countries held in 2002. During a follow-up, online discussion, also hosted by UNESCO, the initial concept was further developed as follows: Open Educational Resources are defined as 'technology-enabled, open
provision of educational resources for consultation, use and adaptation
by a community of users for non-commercial purposes.' They are
typically made freely available over the Web or the Internet. Their
principle use is by teachers and educational institutions to support
course development, but they can also be used directly by students.
Open Educational Resources include learning objects such as lecture
material, references and readings, simulations, experiments and
demonstrations, as well as syllabuses, curricula, and teachers' guides.
(Wiley, 2006, p.23).

Pedagogically, the concept is underpinned by the notion of using resources as an integral method of communication of curriculum in educational courses. However, it is the ease with which digitized content can be shared via the Internet that has the potential to unleash the full power of resource-based learning without bankrupting educational systems. Importantly, as with 'Open Source', the key differentiator between an OER and any other educational resource is its license. Thus, an OER is simply an educational resource that incorporates a license that facilitates reuse - and potentially adaptation - without first requesting permission from the copyright holder. This opens up opportunities to create and share a wider array of educational resources, thereby accommodating a greater diversity of student needs. The digital information, combined with its increasingly widespread dissemination, poses significant challenges to concepts of intellectual property. Copyright regimes and business models for publication are under scrutiny.

As a teacher or a student - to develop an adequate methodology or to learn by doing - , teachers and students need to create and develop learning materials. For this reason, it is really important to use technology as a partner in the teaching and learning process to engage and support thinking and reflection. To this end, the work of Jonassen, Howland, Moore and Marra (2002) provided additional theoretical support highlighting five important principles associated with learning with technology. These principles posit that meaningful learning is active, constructive, goal directed, authentic, and collaborative. The design of OER gives the option to set their own goals and reflect on their progress in an effort to allow them to understand their learning and perhaps apply this learning to new situations in the future. Actual structures of the network, along with many of the resources exchanged in the network, are created by the students themselves. Teachers and students are placed in the role of a producer of content, artifacts, and knowledge requiring them to make decisions and wrestle with 
real issues associated with designing a meaningful personal learning environment. This required each member of a group to achieve a common understanding of the tasks presented and agree on the stages and the methods they would use to achieve the goal of the project.

For this purpose, the open educational resources should be created, including the following characteristics: access/search for information and knowledge; aggregate and scaffold by combining information and knowledge; manipulate, rearrange and repurpose knowledge artefacts; analyze information to develop knowledge; reflect, question, challenge, seek clarification, form and defend opinions; present ideas, learning and knowledge in different ways and for different purposes; represent the underpinning knowledge structures of different artefacts and support the dynamic rerendering of such structures; share by supporting individuals in their learning and knowledge; networking by creating a collaborative learning environment.

\subsection{Role of Teachers in creating, adapting and sharing OER}

The role of the teachers in this new digital context should represent a methodological change and the design of open and well-organized resources must be one of their basic competences. These new materials should encourage greater individual engagement of students with information, ideas and content than is possible with lectures alone. By making such resources an integral part of the teaching and learning process, limited face-to-face teaching time with students can be more effectively used to foster engagement and to nurture discussion, creativity, practical applications, and research activities. In this context, some challenges are suggested for the academic staff in Higher Education (UNESCO, 2011):

1. Develop skills to evaluate OER. A good starting point is to evaluate existing

OER in portals/repositories and determining what might be useful in courses and modules.

2. Consider publishing OER. Begin to design basic materials alone and in small groups and publish these materials openly, including course outlines, course information booklets or hand-outs, teaching notes and course assessment tools and instruments.

3. Assemble, adapt and contextualize existing OER. One of basic competence is to adapt and contextualize existing OER to respond to diverse learning needs of students and support a variety of learning approaches for a given learning goal.

4. Develop the habit of working in teams. To adopt the team approach is the most successful strategy for the development and repurposing of materials.

5. Seek institutional support for OER skills development. There are many academic courses, even more nowadays with MOOCs, to develop skills and competences in order to exploit OER effectively and to apply them to the curriculum development. 
6. Leverage networks and communities of practice. Academic staff should use the existing online networks and communities of practice collaboratively to develop, adapt and share OER, as well as to engage in dialogue about their experiences in teaching and learning. Such communities of practice can also provide an excellent platform for publishing resources in existing repositories.

7. Encourage student participation. Academic staff could encourage students to create, adapt and publish their own OER to develop their own competences.

8. Promote OER through publishing about OER. The promotion of OER created via open publications, journals and other relevant vehicles is one of the best ways to promote these materials.

9. Provide feedback about, and data on the use of, existing OER. Providing feedback and data on the OER that have been created, adapted, used and/or reused, specifically relating to success in meeting learning goals and student needs, is an invaluable contribution to their effective use.

10. Update knowledge of IPR, copyright and privacy policies. It is particularly important to be clear about rights and conditions relating to works created during the course of employment and how these might be shared with and used by others.

\subsection{Role of Students in creating, adapting and sharing OER}

The students of $21^{\text {st }}$ century need to develop an active global citizenship and for that purpose, employability, transferable skills and knowledge, communication skills, creativity and innovation are needed. When OER are adequately supported, students have great potential to support Higher Education providers in sourcing, adapting and producing OER in partnership with academic staff. Although creating teaching and learning environments that harness OER in educationally effective ways is primarily the responsibility of academic staff, student bodies - as key stakeholders in Higher Education - should be aware of the relevant issues and integrate them as appropriate into their interactions with other students. In this context, it is suggested that student bodies (UNESCO, 2011):

1. Understand the issues of OER and undertake advocacy of OER. Students should adopt a producer role as active participants in the learning process.

2. Encourage their members to publish work as OER. Students can make a significant contribution to increasing the use of OER by publishing their work (preferably under the guidance of academic staff and within institutional protocols) under an open license. 
3. Take an active role in assuring the quality of OER through social networks.

Student bodies can encourage students to participate in the social networking environments that have been created around OER repositories, so that they play an active role in assuring the quality of content by adding comments on what content they are finding useful and why.

4. Recognise that ICT are an increasingly important part of the Higher Education experience and are often crucial for students with special educational needs.

5. Encourage student participation in activities to support OER development. Student bodies can help to shape the nature and quality of students' educational experiences by encouraging and supporting the use of OER for the purposes of self-directed study and, at the more advanced levels, by having students create their own curriculum/courses of study.

\section{Semantic, Immersive and Ubiquitous Web for developing rich PLEs}

\subsection{Characteristics of Semantic Web}

The Semantic Web is a vision to provide structured knowledge representation in the web, and this can give new applications for processing information and many of the programs can serve as a foundation for improved interoperability among distributed PLEs. The aim is to improve existing systems to optimize the time required in an advanced search and obtain relevant information to generate new knowledge based on the analysis of the data obtained. Semantic Web can enhance learning networks in areas such as: use of units of learning, the student role and functionality of navigation and information search based on the predominant learning styles.

These activities allow teachers and students to easily identify resources that have particular properties; visualize the relationships between resources, or make interpretations and arguments. The premise for all developers should be to maintain the simplicity of use, building a simple platform with basic tools, easy to use and interoperable among themselves, so that users do not have to learn from scratch to use a new application. An easy navigation interface, tools for creating 3D content will be essential for non-technical users. In this sense, the existence of open specifications and standards on 3D allow anyone to build an application or a virtual world that is connected to another, just as HTML to create a website linked to another.

The role of semantic technologies is slightly different: its main purpose is automation of personalized learning process, improvement of the quality of knowledge representation, searching and knowledge understanding. Semantic Web tools (widgets) include Topic Map(TM) software, and some Web 2.0 and Web 3.0 tools. There are some available TM authoring tools, but they are useful to experts in knowledge representation, not to end users. OntoWiki, for example is a tool providing support for agile, distributed knowledge engineering scenarios. OntoWiki facilitates the visual presentation of a knowledge base as an information map, with different views on instance data. A Semantic Weblog uses Semantic Web technology for improved searching and navigation in the blogosphere. The Semantic Web Widget Libraryis a library for creating user interfaces that work with the Semantic Web. Semantic Web tools (widgets), as light weight ontology editors, annotators, graphical 
browsers, community-driven ontology management tools, integrated in semantic web are needed for collaborative knowledge conceptualization, textual document annotations, verification of the level of knowledge understanding by learners.

\subsection{Characteristics of Immersive Web}

In this web immersive Education is developed through a learning platform that combines interactive 3D graphics, video games, simulation, virtual reality, voice over IP/VoIP, Web cameras, digital media and online classrooms. Immersive Education gives students a sense of being on stage, even when he or she is not present in a class; also provides the possibility to remote students, the ability to connect and communicate in a way that enhances the learning experience. Interactive lessons can be included as a module of a larger system and thus enhance and enrich the Immersive Education experience. The first generation of immersive education was built on the modeling language virtual reality (VRML) and Extensible 3D standards (X3D), while the $2^{\text {nd }}$ generation platform is based on the virtual engine.

The $3^{\text {rd }}$ immersive education platform is being defined by the Education Technology Group Immersive (IETG). Virtual spaces are meeting places where individuals negotiate through discussion, critique, and replication. Assume roles, leadership, shared practices and dynamics of group cohesion, have idiosyncratic elements that are specific to the virtual environment, also suitable for individuals who live there, generating its interaction with basic cultural conditions. An ethnographic method in cyberspace is similar to that applied in the conventional physical media, but with certain adaptations. Two of the more productive strategies and proposals based on Immersive Web are: Design and develop "Web3D Books": Web3D Books are Web-based digital books that support bidirectional interaction with Immersive Education learning experiences. Web3D Books are used to assemble and present any combination of text, imagery (such as images and videos), audio, Web content (HTML pages, Flash animation, etc.), and Web-based 3D content (such as Shockwave and X3D). A Web3D Book can be thought of as a Web-based presentation container that seamlessly guides learners through three-dimensional (3D) immersive learning experiences. Design, develop and promote open and platform-neutral file formats that enable interoperable learning environments to be seamlessly deployed across a wide variety of virtual world and game platforms (e.g., Second Life, World of Warcraft, Open Croquet, Wonderland, There.com, and other 3D/VR platforms).

\subsection{Characteristics of Ubiquitous Web}

If Web 2.0 is the social networking site and Social Media, and Web 3.0 aims to understand and interrelate all existing information on the network, Web 4.0 or ubiquitous will be the one which joins intelligent systems, interlinking people with machines from any location, as all applications that we use will not have to be on our computer, but will get to them in an organized online and from any mobile device. The ubiquitous web allows joint decision making between users and machines by mixing human intelligence with the use of computer programming. It is based on two pillars:

- Natural Language Understanding (NLU) Speech-to-text techniques. New models of machine-machine communication (M2M). The network will consist of intelligent agents in the cloud, you will be able to communicate and delegate the response to the right agent. 
- Using user context information. Sentiment analysis, geolocation, sensors... New model of user interaction. For the Web does not become a mere information store requires new models of interaction, or even execute specific actions that respond to the needs of users, emphasizing its use on mobile devices.

These semantic, immersive, and ubiquitous resources and approaches can be really useful in developing rich PLEs. These personal learning environments have to be enriched with the new emerging technologies.

\subsection{Video-simulation: Learning Modular Mini-videos}

In the new paradigm of Higher Education, the lecturers are considered agents that create work environments to stimulate the students. Moreover, the main factor for learning is the willing of learning and the effort to achieve it. It is clear that the students are the key part in this process. However, the lecturer can and must help him/her, facilitating and guiding his/her autonomous learning. In this training context teachers tend towards the design and use mini-videos that video-simulate, explain, and summarize content. This trend is being witnessed in MOOCs in PLEs and also, increasingly, in university subjects developed in LMS (Daniel, et al., 2015; Aguaded, et al., 2016).

In order of achieving this approach, different authors have proposed using a new teaching tool based on mini-videos for self learning that uses an electronic blackboard. The way to reach this concept has been through an evolution from the recording of a whole lecture, across producing videos for exercises and finally ending with the concept of mini-videos. The mini-videos are based on the philosophy of "I work (the lecturer)", "You work" (the student). They are constructed with the help of minimalist slides that are filled out with the help of the electronic blackboard. The success of the "learning to learn" approach will be based if lecturers and students accept, understand and assume the philosophy: I work, you work. If both work, in class and outside the class, the "learning to learn" approach will succeed, but if one of them does not do it, it will fail. This philosophy is part of the mini-videos and brings several advantages for the student and for the lecturer.

The main advantages for the student are:

- He/she can choose the time, the place and the rhythm of learning.

- He/she has a comprehensive material

- He/she can re-enter in the subject whenever he/she wants.

- He/she can prepare easily the continuous evaluation.

- There is a real possibility of distance learning.

The main advantages for the lecturer are:

- Planning can easily be done.

- The lecturer can be more proactive

- The lecturer does not have the sense of time oppression. 
- It helps to strengthen the contact with the student.

- It helps the implementation of continuous evaluation.

- The coordination between lectures and practical sessions is optimal.

- There is a real possibility of distance learning.

\subsection{Digital resources for creating PLESs}

One of the simplest ways to start creating a PLE is via social networking tools, and in particular blogs and wikis. These simple publishing platforms can be used for a range of learning activities and are generally free or very low-cost. For example, the following tools and techniques could be used as first steps to creating your PLE (UNESCO, 2011):

- Create a blog and publish notes and resources relevant to students or colleagues. Invite others to comment and reflect on the ideas shared.

- Create a wiki and publish resources and information to share with students or colleagues. Include links to other websites and resources.

- Join Twitter and share ideas and information with members of your Twitter network. Follow \#hashtags or use the Twitter Search tools to search for topics of interest and locate other Twitter users you can follow.

- Join an Educators Network and share thoughts using forum or group discussion tools. Share ideas, lesson plans and other resources with colleagues.

- Record learning activities or educational events via photograph or video and publish the results on a social networking site like Flickr or Youtube. Invite others to share and comment on your work.

- Join an Education Network on Facebook and contribute to the information and resource sharing.

- Setup an RSS Reader Tool and subscribe to blogs and other websites that are of professional interest. Make comments and share your responses in the comments section.

- Watch the video included here, which was created by a 7th Grade Science student and provides an overview of her Personalized Learning Environment and the impacts it has had on her learning. Consider how you could use these strategies with your students.

From this perspective it is basic to implement a "Team-Based Design" of PLEs. A key aspect of the team-based design is the move beyond individualistic approaches to course innovation. In Higher Education, we have long invested in the 
notion that the way to innovate is by converting faculty. This move represents a shift in strategy: instead of trying to change faculty so that they might change their courses, this model focuses on changing course structures so that faculty will be empowered and supported in an expanded approach to teaching as a result of teaching these courses (Bass, 2012). The idea is to explore individually and afterwards in groups different 2.0 tools in specific tasks, but integrate them into the normal work dynamic of students, and each time find ways to use them in the group-work proposal. Basically, students have to integrate those tools into their Personal Learning Environments to construct their own knowledge.

\section{Conclusions}

If we want to design a work based PLE it is necessary to understand the contexts in which learning take place and the different discourses associated with that learning. A PLE is both able to transpose the different contexts in which learning takes place and can move from one domain to another and make connections between them. As we showed in this chapter, it can support and facilitate a greater variety of relationships than traditional educational media. At the same time, a PLE is able to support a range of learning discourses including discourses taking place within and between different communities. An understanding of the contexts in which learning takes place and of those different learning discourses provides the basis for designing key tools to develop knowledge on a PLE. Indeed, one of the most powerful aspects of today's technologies is that many of the high-impact features that used to be possible only in small classes can now be experienced not only at a larger scale but, in some cases, to better effect at larger scale.

We need to acknowledge that the center of significant learning has shifted to a new, recentered core and that, from the perspective of deep learning and impact, most of the formal curriculum now must move from margin to center. We need to think more about how to move beyond the individualistic faculty change model and get involved in team-design and implementation models on our campuses, and we need to consider that doing so could fundamentally change the ways that the burdens of innovation are often placed solely on the shoulders of faculty. The learning we are coming to value most is not always where we are putting our greatest interest and effort in assessment, including the emerging discussions about "learning analytics".

In this context, the potential of OER brings transparency to educational processes, facilitating collaborations between educators and students at different institutions, and establishing a new economic model for procuring and publishing learning materials. OER will help over-stretched educators to manage their work more effectively, rather than adding new work requirements to their job description. However, successful OER initiatives will be those that can work immediately and add educational value within the existing ICT infrastructure constraints of any participating institutions (including those from the developing world). Proving the potential of a concept that will only have an impact when these infrastructural constraints are removed is of little value to Higher Educational institutions in the short to medium term. Sharing materials that others can adapt and use recognizes the value inherent in team work and the improvements in thinking that will emerge from such collaboration.

Doing this openly, using the already proven innovations of the Internet to facilitate sharing of content, presents a practical way to use cooperation to find simple solutions to pressing problems we face in education. As with all such communal processes, the initial results will be messy - and there will be many problems to solve, 
such as how to create appropriate curriculum frameworks for storing content, and mechanisms to help with assessing quality. But online communities have demonstrated the now indisputable power and value of lots of people working collaboratively towards a common cause. And doing this in education has the potential to re-focus educational systems, restoring the core values of building and sharing knowledge that underpin good education, and systematically encouraging us to work with and learn from one another.

\section{References}

Aguaded, I., Vázquez-Cano, E., \& López Meneses, E. (2016). El impacto bibliométrico del movimiento MOOC en la Comunidad Científica Española. Educación XX1, 19(2), 77-104.

Alloway, T., Horton, J., Alloway, R. G., \& Clare Dawson (2013). Social networking sites and cognitive abilities: Do they make you smarter? Computers \& Education, $63,10-16$.

Attwell, G. (2007). Personal learning environments -the future of eLearning? eLearning Papers, 2(1).

Attwell, G. (2010). Context and the design of Personal Learning Environments. Barcelona: PLE2010 Conference.

Bass, R. (2012). Disrupting Ourselves: The Problem of Learning in Higher Education. Educause Review, March/April.

Castañeda, L., \& Soto, J. (2010). Building Personal Learning Environments by using and mixing ICT tools in a professional way. Digital Education Review, 18, 9-25.

Cheung, R., \& Vogel, D. (2013). Predicting user acceptance of collaborative technologies: An extension of the technology acceptance model for e-learning. Computers \& Education, 63, 160-175.

Daniel, J., Vázquez-Cano, E., \& Gisbert, M. (2015). The future of MOOCs: Adaptative Learning or Business Model? RUSC. Universities and Knowlwdge Society Journal, 12(1), 64-73.

Downes, S. (2007). Open Educational Resources and the Personal Learning Environment. Taipei, Taiwan. Retrieved from http://www.slideshare.net/Downes/open-educational-resources-and-the-personallearning-environment 
Downes, S. (2010). New Technology Supporting Informal Learning. Journal of Emerging Technologies in Web Intelligence, 2(1).

Drexler, W. (2010). The networked student model for construction of personal learning environments: Balancing teacher control and student autonomy. Australasian Journal of Educational Technology, 26(3), 369-385.

Fuchs, C. (2005). CMC-based model learning in language teacher education: A German-American telecollaboration. In Thompson, I., \& Hiple, D. (Eds.). Selected papers from the 2004 NFLRC symposium: Distance Education, Distributed Learning and Language Instruction (pp.141-156). Honolulu: University of Hawaii, National Foreign Language Resource Center.

Griff, E. R., \& Matter, S. F. (2013). Evaluation of an adaptive online learning system. British Journal of Educational Technology, 44, 170-176.

Hall, G. E. (2010). Technology's Achilles Heel: Achieving High-Quality Implementation. Journal of Research on Technology in Education, 42(3), 231-253.

Johnson, M., \& Liber, O. (2008). The personal learning environment and the human conditions: From theory to teaching practice. Interactive Learning Environments, 16(1), 3-15.

Jonassen, D. H., Howland, J., Moore, J., \& Marra, R. M. (2002). Learning to Solve Problems with Technology: A Constructivist Perspective. Columbus, $\mathrm{OH}$ : Merrill/Prentice Hall.

López Meneses, E., Vázquez-Cano, E., \& Fernández Márquez, E. (2014). Análisis de la percepción de los alumnos sobre las áreas de intervención del futuro educador y trabajador social a través de una didáctica digital con mapas conceptuales multimedia. RED. Revista de Educación a Distancia, 41, 1-17.

López Meneses, E., Vázquez-Cano, E., \& Román, P. (2015). Analysis and implications of the impact of MOOC movement in the scientific community: JCR and Scopus (2010-2013). Comunicar, 44, 73-80.

Martindale, T., \& Dowdy, M. (2010). Personal Learning Environments. In Veletsianos, G. (Ed.), Emerging technologies in distance education, 177-193. Edmonton: AU Press. 
Martín-Monje, E., Vázquez-Cano, E., \& Fernández, M. (2015). Peer assessment of language learning resources in virtual learning environments with e-rubrics. International Journal of Technology Enhanced Learning, 6(4), 321-342.

Mercier, E. M., \& Higgins S. E (2013). Collaborative learning with multi-touch technology: Developing adaptive expertise. Learning and Instruction, 25, 13-23.

Sánchez E., \& García-Rodicio, H. (2013). Using online measures to determine how learners process instructional explanations. Learning and Instruction, 26, 1-11.

Severance, C., Hardin, J., \& Whyte, A. (2008). The coming functionality mash-up in personal learning environments. Interactive Learning Environments, 16(1), 47-62.

Sevillano, M. ${ }^{a} L, \&$ Vázquez-Cano, E. (2015). The impact of digital mobile devices in Higher Education. Educational Technology \& Society, 18(1), 106-118.

Sevillano, M. ${ }^{a} L .$, \& Vázquez-Cano, E. (2015). Modelos de investigación en contextos ubicuos y móviles en Educación Superior. Madrid: McGraw-Hill-Education.

Singh, V., \& Holt, L. (2013). Learning and best practices for learning in open-source software communities. Computers \& Education, 63, 98-108.

Van Harmelen, M. (2008). Design trajectories: Four experiments in PLE implementation. Interactive Learning Environments, 16(1), 35-46.

Wiley, D. A. (2006). The Current State of Open Educational Resources. Paper for Expert Meeting on Open Educational Resources, OECD.CERI, Malmö (6-7 February 2006).

Wilson, S. (2008). Patterns of Personal Learning Environments. Interactive Learning Environments, 16(1), 17-34.

UNESCO (2011a). Guidelines for Open Educational Resources (OER) in Higher Education. UNESCO. Commonwealth of Learning.

UNESCO (2011b). A Basic Guide to Open Educational Resources (OER). UNESCO. Commonwealth of Learning.

Vázquez-Cano, E. y Sevillano, M. ${ }^{a}$ L (2011). Educadores en Red. Elaboración de materiales audiovisuales para la enseñanza. Madrid: Ediciones AcadémicasUNED. 
Vázquez-Cano, E., Fombona, J., \& Fernández, A. (2013). Virtual Attendance: Analysis of an Audiovisual over IP System for Distance Learning in the Spanish Open University (UNED). The International Review of Research in Open and Distance Learning (IRRODL), 14(3), 402-426.

Vázquez-Cano, E. (2014). Mobile Distance learning with Smartphones and Apps in Higher Education. Educational Sciences: Theory \& Practice, 14(4), 1-16.

Vázquez-Cano, E., \& Sevillano, M.'․ (2015). Dispositivos digitales móviles en Educación. El aprendizaje ubicuo. Madrid: Narcea.

Vázquez-Cano, E., Martín-Monje, E., \& Castrillo, M.ㄹD. (2016). Analysis of PLE's implementation under OER design as a productive teaching-learning strategy in Higher Education. A case study at Universidad Nacional de Educación a Distancia. Digital Education Review, 29, 62-85. 